\title{
Educational material for the patient with leprosy
}

\author{
A C MCDOUGALL* \& G D GEORGEIV† \\ 87 Lower Radley, Near Abingdon, Oxfordshire OX14 3BA, \\ England; †275 Turnpike Drive, Luton, Bedfordshire LU3 3RD, \\ England
}

\section{Accepted for publication 21 April 1989}

\begin{abstract}
Summary This paper addresses the need for suitably written and illustrated material for the patient with leprosy with emphasis on the effective administration of WHO recommended multiple drug therapy (MDT) and the prevention of deformities. The successful implementation of MDT strategy for leprosy control calls for attention to a 'package' of activities, amongst which the education of the patient regarding the disease and its modern treatment may be of crucial importance. Attention is drawn to the steady improvement in educational and literacy levels in many developing countries and to the potential of clearly written instructions for use by patients and staff. The importance of development of educational material in the context of the regional and local cultural milieu is stressed. Eight major 'messages' related to the causation of the disease, the importance of regular clinic attendance for monthly supervised drug administration, compliance to the daily domiciliary drug intake and action for prevention of disability, are proposed. These 'messages' are accompanied by outline drawings which can be used by staff for patient education both at the onset of chemotherapy and on the subsequent clinic attendances. The paper describes broad approaches but underlines the importance of local development of educational material for this purpose.
\end{abstract}

Not only for leprosy, but also for many other conditions in both developed and Third World countries, it has for long been recognized that the supply of educational material for patients, particularly with regard to compliance to prescribed medication, is either defective or non-existent. If one defines compliance as a combination of satisfactory intake of prescribed medication, regular attendance for supervised medication and/or clinical examination and adherence to any given regimen for an adequate period of time, the world problem of non-compliance in diseases such as high blood pressure, diabetes, glaucoma, schizophrenia, arthritis, epilepsy, leprosy, tuberculosis (and many more) is immense. Where early diagnosis and drug treatment are the basic means of control of diseases, as in leprosy and tuberculosis, patient compliance, using the above definition, is clearly of critical importance. The literature on this subject is enormous; since the early days of the 
production and clinical use of effective chemotherapeutic agents, the difficulties in persuading patients to follow prescribed courses of treatment (even for short courses) have been recognized and attempts made to analyse the causes and devise remedies. Many reviews of the subject have drawn attention to the fact that the overall rate or level of 'compliance' for a wide range of medication in different diseases, is deplorably low. ${ }^{15}$ The losses in terms of benefit to patients and the national drug budget are self-evident.

The magnitude of this problem and the need to develop educational material for patients had been recognized by WHO and other international agencies over the years. In 1985, the WHO Action Programme on Essential Drugs and Vaccines ${ }^{6}$ convened a meeting at which a working group examined the possibilities for the development of more effective written and illustrated material. They drew attention to 5 important steps to ensure the proper use of drugs, namely: accurate diagnosis, rational prescription, correct dispensing, suitable packaging and clear instructions to the patient. Two main approaches by way of strategy for improvement were identified: 1, the communication of 'general principle' messages through all appropriate institutions using a 'campaign' approach, and 2, communication of specific information for individual drugs through message communicators. The Report of this important workshop covers the production and use of both written and illustrated material, drawing attention to the numerous pitfalls, making it essential reading for anyone involved in health education for the proper use of essential drugs.

In the case of tuberculosis, the crucial importance of a regular and satisfactory drug intake in achieving clinical cure in individuals and breaking the chain of transmission has been well recognized since the early days of combined therapy for that disease. The problem of compliance with the self-administration of drugs in tuberculosis control has been reviewed in detail ${ }^{7,8}$ and recently attention has been drawn to the continuing problems, even with short-course regimens. ${ }^{9}$ In leprosy, numerous studies have been published through the years, ${ }^{10-14}$ including the era of dapsone monotherapy, calling attention to the deficiencies of self-administered medication, regularity of attendance and adherence to the regimen for a sufficiently long period of time. Recently attention has been drawn to the need for the more effective application of available techniques in social and clinical psychology for the study of this problem..$^{15,16}$

Much of what we have said so far refers only to the matter of drug treatment in leprosy, but we propose to expand the approach and to make outline proposals which cover: a, the supply of basic information on leprosy to the patient; $b$, the development of educational material to improve attendance and drug intake; and c, similar material to prevent, and perhaps also to treat disability and deformity, thus maintaining the principle of combined 'bacillus control' and 'disability control ${ }^{17}$ with emphasis on what can be achieved in the community. ${ }^{18}$

\section{Basic information}

The enormous variations in educational levels, cultural patterns and attitudes to disease which are likely to be encountered in leprosy programmes make it impossible to put forward, in any detail, a universally applicable set of statements. The general principles of communication with patients have been clearly spelled out and the importance of understanding local attitudes, beliefs and behaviour for the purpose of health education has been emphasized. ${ }^{19}$ The basic information should be succinct and brief, unemotional, objective and realistic, focusing on the important facts and presented in correct order ${ }^{20} \mathrm{It}$ is also vital to develop this information through indigenous workers with a knowledge of leprosy, who also have a good grasp of the cultural and socioeconomic conditions of their own people. 'Pre-testing' and testing of any package of information is essential before anything goes to printing and distribution. Teaching and learning materials for virtually all grades of worker in leprosy have been developed extremely well, ${ }^{21}$ and on a scale which outclasses almost any other communicable disease, but very little has been developed for the patient. This may be significant; it is certainly not easy to do it effectively and mistakes can easily be made. But the 
need, for the involvement of the patient (as also the family and the community) in case detection and the better use of multiple drug therapy (MDT), as recommended by WHO in $1982,{ }^{22}$ is outstanding - and needs attention. Patients are not fools; literacy rate in some leprosy endemic countries are surprisingly high $^{23}$ and we should pursue the possibility that patients, either by themselves or with the family, make good use of instructions leading to cure and the avoidance of deformity. The case for at least devising and trying out written and illustrated material for this purpose seems to us to be overdue.

\section{Educational material to encourage the better use of drugs}

In the WHO document referred to above, ${ }^{6}$ attention was directed to the problems associated with correct use of drugs, assuming that diagnosis, prescription, dispensing and packaging were appropriate, and a variety of 'target groups' for such material were identified, including caretakers/ parents of children, pregnant women, adults and the elderly. The working group further considered the framework (health infrastructure, non-governmental or voluntary organization, schools, etc.) through which educational material should be channelled, whilst emphasizing the importance of development of such material with (a) the active participation of the target audience, and (b) advice, where appropriate, from experienced prescribers, dispensers and pharmacists. They also listed the many ways in which the messages can be presented: written material in books, pamphlets, with or without simple illustrations, posters, slides/tapes; television/video, radio, cinema and live performances. These approaches are all potentially valuable but in the present communication we shall concentrate on the production of simple, written information, possibly supported by illustrations which may be useful for local development.

To develop relevant written materials for the effective education of the patient with the aim of improving participation in the treatment and cure process, the following questions need consideration:

What does the patient need to know about the disease and its treatment?

What is the level of ability of the health/leprosy worker in communication and the education of the patient?

What is the best and most practical means of educating the patient, including educational aids?

The educational process of the patient must begin at the time when the patient is told of the diagnosis and treatment is instituted. It is important to recognize the possibility of psychological trauma associated with a verdict which concerns not only health but also social status. Perhaps this is the most difficult time for the patient and the need for understanding and support by the health worker and the family is essential. This is the moment when confidence in the service and the treatment, including a close partnership between health worker and patient has to be established. The main content of this 'first encounter' has been clearly defined elsewhere. ${ }^{24}$ Particularly in the context of the increasing use of MDT, we offer the following as a check-list to enlisting the cooperation of the leprosy patient as an active partner in the management of the disease and prevention of disability.

Causation of leprosy. Traditional beliefs about leprosy and its causation are often responsible for a lack of faith in modern treatment. It is therefore important for the patient to accept information about the 'germ' cause, the methods of transmission of the disease and the need to adhere to prescribed treatment for an adequate period of time. Knowledge of religion, regional attitudes, beliefs and behavioural patterns is essential. The possibility of illustrating the 'germ concept' will be discussed below.

Medication. The patient needs information about the treatment-when and how much to take, for how long and how it will help him. Warnings must also be given about likely side-effects (e.g. discolouration of urine and/or skin, gastrointestinal upset etc.) and their significance. In 
monotherapy leprosy control, the name of dapsone was widely known to patients and families and the advice about its use was relatively easy. However, the administration of MDT is more complicated and this is particularly so for multibacillary cases, since besides the supervised monthly doses of rifampicin and clofazimine, the patient has to take two types of drugs at home (dapsone and clofazimine). The importance of regular monthly clinic attendance and strict adherence to the daily intake of domiciliary treatment needs persuasive explanation including the use of the 'double check' technique ${ }^{25}$ to achieve maximum understanding by the patient. Field experience, at least at some areas, has shown that health workers encounter difficulties in instructing the patients on MDT ${ }^{26}$ In this context, the potential value of blister calendar packs should be kept in mind. ${ }^{27}$

Suggested written materials for WHO recommended MDT regimens for MB and PB leprosy are outlined in Tables 1 and 2 respectively. It bears repetition that these are intended as outline 'examples', entirel y open to discussion and development by local advisers. We envisage these messages being printed on paper or card as a pamphlet or leaflet, easily folded or accommodated in a pocket and 'linked' to the drugs in their container or blister-calendar pack, notably by colour. Thus, in order to avoid confusion between PB and MB regimens, and perhaps also between child and adult regimens, the use of the same colour scheme for: 1 , the container or blister-calendar pack; 2 , the written instructions to the patient; and 3, the patient record card, would be an obvious additional advantage for all concerned-and almost certainly worth the small additional expenditure. We repeat that personal communication over and above any 'devices' which are provided for the better use of drugs by patients, is absolutely essential. The equation: good personal communication plus

Table 1. Educational material for the patient with multibacillary leprosy

1 Your kind of leprosy disease is called 'MB'. It is caused by a tiny germ which hides in your body and causes the patches and lumps on your skin.

2 You can be cured by new, strong medicines. If you take them regularly, you should not develop any further trouble with your skin, eyes, hands or feet and your leprosy disease will be cured.

3 AT THE CLINIC (TREATMENT CENTRE), every month, you have to take:

3 egg-shaped brown capsules

2 long red capsules

1 white tablet

The doctor or health worker must see you swallow them.

After you swallow them, they join together to kill the germs in your body.

4 AT HOME, every day, you must take:

1 brown, round capsule (clof azimine)

1 white tablet (dapsone)

This daily treatment at home is important in order to stop any new germs growing in your body.

5 This treatment, at the CLINIC and AT HOME, must continue for at least 2 years.

Go every month to the clinic and take your medicine, every day, at home.

Some of the germs hide from the drugs and it takes a long time to kill them all.

6 If you take your treatment regularly, the patches and lumps will begin to go away after 4-6 months. But even when you can no longer see them, continue taking your medicines, until told to stop.

7 If you had def ormity of eyes, hands or feet, perhaps with loss of feeling, before starting treatment, there may not be improvement in the deformity. But the treatment will kill the germs in your body and if it is taken regularly for at least 2 years the deformity is unlikely to get worse.

8 If you think that the treatment is not agreeing with you, report as soon as possible to the clinic (treatment centre) or a hospital. This ref ers especially to:

(a) pain, tingling or loss of sensation in the hands or feet;

(b) loss of strength (power) in the muscles of the arms or legs, or the face;

(c) unexplained fever;

(d) yellowness of skin and eyes (jaundice); and

(e) unexplained weakness. 
Table 2. Educational material for the patient with paucibacillary leprosy

1 Your kind of leprosy disease is called 'PB'. It is caused by a germ which hides in your body and causes patches or marks on your skin, perhaps with loss of feeling and weakness of muscle.

2 You can be cured by new, strong medicines. If you take them regularly, you should not develop any further trouble with your skin, eyes, feet or hands and your leprosy disease will be cured.

3 AT THE CLINIC (TREATMENT CENTRE), every month, you have to take:

2 long red capsules

1 white tablet

The doctor or health worker must see you swallow them.

After you swallow them, they work together to kill the germs in your body.

4 AT HOME, every day, you have to take:

1 white tablet (dapsone)

This daily treatment at home is important to stop any new germs growing in your body.

5 This daily treatment, at the CLINIC and AT HOME, must continue for 6 months.

Go every month to the CLINIC and take your tablet every day at home.

Some of the germs hide from the drugs. So it is important to continue for the full 6 months.

6 If you take your treatment regularly, the marks on your skin will usually disappear in about 6 months.

Do not be worried if your skin is not completely normal in colour after 6 months of treatment. It may take a little longer.

Be patient, and the colour will soon return to normal.

7 If you had deformity of eyes, hands or feet, perhaps with loss of feeling, before starting treatment, there may be no improvement in the deformity. But the treatment will kill the germs in your body and it is therefore important to take it for 6 months, as described above.

8 If you think that the treatment is not agreeing with you, report as soon as possible to the clinic (treatment centre) or a hospital. This refers especially to:

(a) pain, tingling or loss of sensation in the hands or feet;

(b) loss of strength (power) in the muscles of the arms or legs, or the face;

(c) unexplained fever;

(d) yellowness of skin and eyes (jaundice); and

(e) unexplained weakness.

appropriate, clearly written and illustrated instructions plus a suitable container for the drugs is likely, if only on common-sense grounds, to have a significant effect on many aspects of 'compliance', as defined above.

Finally, illustrated material, as shown in Figure $1(\mathrm{a}-\mathrm{d})$, and again entirely subject to local development and trial, may usefully reinforce written messages for patients on MDT. Those shown here are somewhat Africa-orientated and may be unacceptable elsewhere. But if suitably modified, they might be useful for patients and possibly also for health education by the staff. The 'devil' or 'monster' figure which may, in some cultures, identify with a disease-producing organism or germ, but if used at all as part of the basic information described above, pre-testing, preferably by a local sociologist or psychologist is essential.

Duration of treatment and expected results. The WHO recommended MDT regimens for both $\mathrm{PB}$ and $\mathrm{MB}$ forms of leprosy are significantly shorter in duration in comparison with monotherapy, and this seems to be an important factor in the impressive improvement in treatment compliance now seen with these regimens. It is of crucial importance that the patients understand the significance of the duration of treatment and its relation to the ultimate result of this treatment. The second question of importance is the patient's expectation of the prescribed medication. In the case of PB patients, treatment has, in some instances, to be terminated before the skin lesions have completely waned, giving the patient the impression that he is denied treatment when still needing it. Although sometimes resolved by continuing treatment with dapsone alone or by prescribing a placebo, this is not standard WHO advice; adherence to the recommended period, backed by 


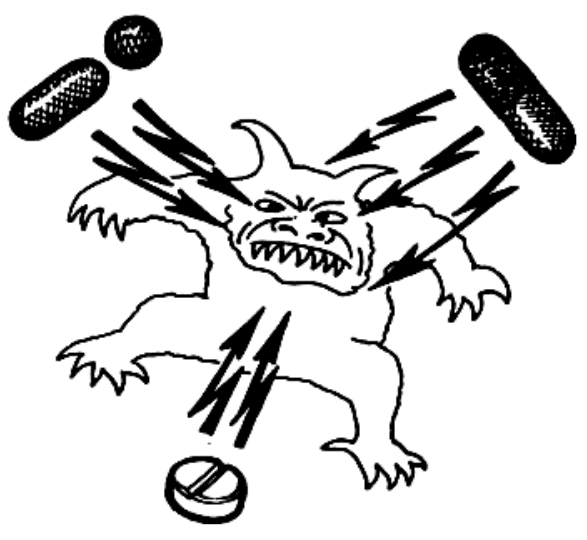

a

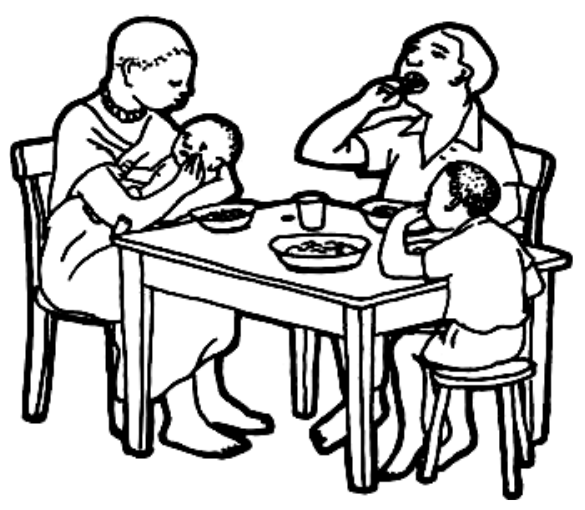

C

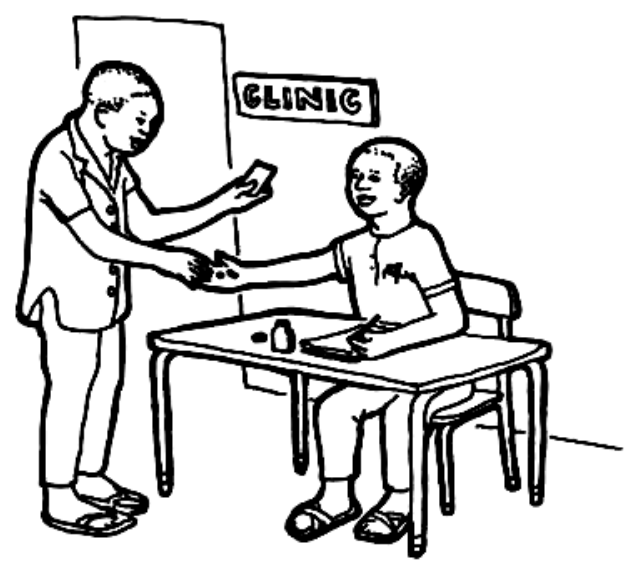

b

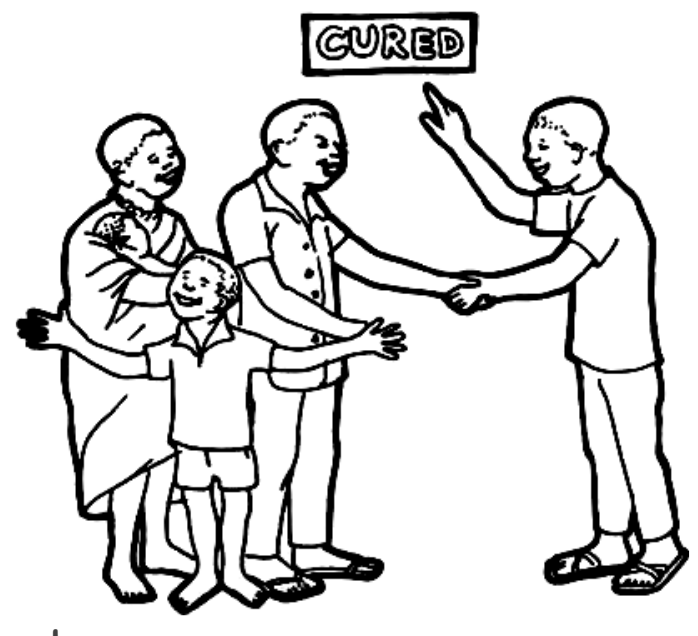

d

Figure 1. These four drawings are presented as a basis for local development or adaptation, to reinf orce the eight messages in Tables 1 and 2. (a) Is intended as a 'devil' or 'monster' figure which may, in some cultures, convey the idea of a 'germ' causing leprosy (message 1) which can be killed by modern drugs (message 2). Note: three drugs are shown in this drawing (dapsone, clofazimine and rifampicin) and this refers to the treatment of multibacillary leprosy. A modification showing only two drugs (dapsone and rif ampicin) would be needed for paucibacillarly leprosy. (b) Is related to the regular monthly clinic attendance for supervised medication, the supply of drugs for home treatment (message 3) and the reporting of any side-effects or early signs of reaction (message 8). (c) Emphasizes the importance of daily, unsupervised drug intake at home (message 4). (d) Illustrates the likelihood of cure if medication is taken regularly and for the prescribed period (messages 6 and 7 ). 
careful clinical follow up and explanation to the patient of his status is preferable, even if more difficult.

With MB cases the situation might be quite the opposite - the clinical signs may completely resolve in 12-16 months and the patient then sees little reason to continue medication. In both cases, personal communication is the key to persuading the patient to respect the prescribed period of treatment. Another important but neglected aspect of the education of leprosy patients centres on the expectation of treatment with particular reference to deformity. Many patients, who had some deformity at the outset of treatment or who develop it during the course of treatment, may consider themselves as not cured, although they have 'completed' the treatment and became bacteriologically negative. The persistence of deformity despite regular treatment may be regarded by the patient, family and community as a failure of the drugs to cure the disease. It is thus essential that the expectations of chemotherapy, especially when deformity is established before MDT, are carefully explained to both patients and family.

The prevention of deformity and disability. The prevention of disability and deformity is an integral part of leprosy control; physical and social rehabilitation cannot be separated from the process of diagnosis, drug treatment and clinical management. Valuable teaching-learning materials on the prevention of disability in leprosy patients and the essential action which is needed to minimize disability are readily available. ${ }^{28,29}$ Although written essentially for use by health staff, these documents are profusely illustrated with diagrams and line drawings and contain much information and advice which could be useful, almost without modification for patients. They also have great potential value for health education between staff and patients and as support material for the current strategy for the prevention of disability and the physical rehabilitation of leprosy patients. ${ }^{30.31}$ The extent to which such information can be extended into the early recognition by the patient of symptoms which may herald the onset of adverse immunological reactions is beyond the scope of this communication, but calls for further study. If patient/staff ratios are favourable and educational levels high enough, there may well be scope for improvement in this area, as also the earlier recognition and treatment of 'silent' neuritis. ${ }^{30}$

\section{Conclusion}

We have recorded some ideas for the development of educational materials for patients with leprosy, whilst keeping in mind the pitfalls of any approach which is not locally orientated and tested out before being put into use. We are also conscious of the fact that good health education requires skills and ability and that the basic training of health workers in this important aspect of their work has been neglected. If our emphasis on attractive drug presentation, together with written and illustrated material, seems too strong, this is at least partly due to our concern about the increasing demands which are being made on the time of paramedical, nursing and community health workers. But the potential of MDT in the control of leprosy is now so great that it is no longer acceptable simply to diagnose this condition and send people away with handful of tablets and capsules. At the very least, each patient needs a few minutes of personal communication and it is beyond doubt that the effect of this will be reinforced by suitable, well thoughtout written and illustrated material. Many of us have textbooks, libraries, computerized information systems and journals. Peripheral health staff (whose actual needs are considerable) have very little, and patients even less. Perhaps we should put more money and effort into the identification and training of local people to develop educational material not only for leprosy but also for other diseases in relation to the WHO Essential Drugs Programme.

\section{Acknowledgments}

We are grateful to Patricia Georgiev for devising the pictures used in this publication and to David 
Webster of the Department of Medical Illustration, the John Radcliffe Hospital, Oxford, for developing them further.

\section{References}

1 Davis MS. Variations in Patients' Compliance with Doctors' Orders: Analysis of Congruence Between Survey Response and Results of Empirical Investigations. J Med Educ, 1966; 41: 1037-48.

Marston MV. Compliance with Medical Regimens. A review of the Literature. Nurs Res, 1970; $19: 312$.

Mikeal RL, Sharpe TR. Patient Compliance. In Pharmacy Practice-Social and Behavioural Aspects. Wertheimer AI, Smith MC (eds), University Park Press, Baltimore, Maryland, USA, (1975).

${ }^{4}$ Haynes RB, Wayne Taylor D, Sackett DL (eds). Compliance in Health Care. John Hopkins University Press, Baltimore and London (1979)

5 Office of Health Economics. 'Keep on taking the tablets-a review of patients non-compliance.' OHE briefing, 4, 1983.

${ }^{6}$ WHO. Report of an informal working group in educational material for patients convened by the WHO Action Programme on Essential Drugs hosted by the WHO South-East Asia Regional Office, New Delhi, 21-25 October, 1985. DAP/85.10

${ }^{7}$ Fox W. Self-Administration of Medicaments: a review of published work and a study of the problem. Bull Int Union Against Tuberculosis, 19 ; 32: 2, 307-31.

8 Fox W. Compliance of patients and physicians: experience and lessons from tuberculosis. Brt Med J, 1983, part I, 283; 33-5; part II, 287: 101-5.

${ }^{9}$ Fox W. Tuberculosis case finding and treatment programmes in the developing countries. In Tuberculosis and Leprosy. Scientific Editor: Rees RJW. Edinburgh: Churchill Livingstone, 1988.

${ }^{10}$ Giel R, Van Luijk JN. Leprosy in Ethiopian Society. Int J Le pr, 1970; 38: 187-98.

11 Ellard GA, Pearson JMH, Haile GS. The self-administration of dapsone by leprosy patients in Ethiopia. Lepr Rev, 1981; 52: 237-43.

12 Hertoijs AR. A Study of Some factors Affecting the Attendance of Patients in a Leprosy Control Scheme. Int J Lepr, 1974; 42: 419-27.

13 Ellard GA. Drug Compliance in the treatment of Leprosy. Lepr Rev, 1981; 52: 419-27.

14 Langhorne P, Duffus P, Berkeley JS, Jesudasan K. Factors influencing attendance during the multidrug therapy of leprosy. Lepr Rev, 1986; 57: 17-30.

15 Vadher A. The relevance of clinical and social psychology in leprosy control and management. Thesis for the degree of Doctor of Philosophy. The University of Oxford. In preparation. 1989.

16 Vadher A. Factors influencing clinic attendance for treatment of leprosy. Abstract FA 228, Abstracts of the 13th International Le prosy Congress. The Hague, Netherlands. Quaderni di Cooperazzioni Sanitaria, 1988; 9.

17 Watson JM. The Leprosy Mission International, London: Personal communication, 1986.

18 WHO. Training Disabled People in the Community. A manual on community based rehabilitation for developing countries. WHO, and other international agencies, Geneva, 1983.

19 WHO. A Guide to Leprosy Control. Second Edition. World Health Organization, Geneva, 1988.

20 Rubenson, B. Health Teaching Made Easier. How to Create a Manual. Contact No. 105, 1-7, October 1988.

21 TALMILEP. Teaching and learning in leprosy. English language booklist. ILEP(International Federation of Anti-leprosy Associations. Steering Committee on Teaching \& learning Materials, Wurzburg, West Germany. 1988.

22 WHO. Chemotherapy of leprosy control programmes. Report of a WHO Study Group. Technical Report Series No. 675. World Health Organization, Geneva, 1982.

${ }^{23}$ UNICEF. The State of the world's Children. Education, Table 4. Information and public Affairs. UNICEF House, 3 UN Plaza, N. York.

24 Neville PJ. A guide to health education in leprosy. ALERT.

25 Ross WF. Helping patients take their pills. The Star, 1981; 41: 1, 2-3.

26 Valentia LB. Leprosy — as seen by the patients. Wld Hlth Forum, 1988; 1: 59-67.

27 Georgiev GD, McDougall AC. Blister calendar packs: potential for improvement in supply and utilization of multiple drug therapy in leprosy control programmes. Editorial. Int J Lepr, 1988; 56: 4, 603-10.

28 Watson JM. Preventing disability in leprosy patients. The Leprosy Mission International, London, 1986.

29 Watson JM. Essential Action to Minimise Disability in Leprosy Patients. The Leprosy Mission International, London, 1986.

30 WHO. Expert Committee on Leprosy. Sixth Report. Technical Report Series No. 768. World Health Organization, Geneva, 1988.

31 Wheate HW. Management of Leprosy. In: Tuberculosis and Leprosy. Br Med Bull, Published for the British Council by Churchill Livingstone, Edinburgh, 1988. 